\title{
Evaluación espacio temporal de la contaminación por partículas suspendidas totales en las parroquias del área metropolitana del municipio Maracaibo, Venezuela, $2001 \sim 2008^{1}$
}

Temporary space evaluation of the total suspended particles pollution in the metropolitan area parishes in Maracaibo, Venezuela. 2001 2008.

Eloy Montes Galbán ${ }^{2}$ Cecilia Hurinson Prettes ${ }^{3}$

\section{Resumen}

Con este estudio se hizo una evaluación espacio-temporal de la contaminación por partículas suspendidas totales en las parroquias del área metropolitana del municipio Maracaibo, durante los años 2001-2008. Con tal propósito, fueron empleados los siguientes datos: los de contaminación por PST (concentraciones promedio anual) registrados por el Instituto para el Control y la Conservación de la Cuenca del Lago de Maracaibo (ICLAM) y las estadísticas demográficas (Censo 2001). A través de Sistemas de Información Geográfica (SIG) se aplicaron métodos de análisis espacial a las diferentes capas. Para el año 2001, el contaminante PST era moderado y se distribuía de forma homogénea en el $98 \%$ de la superficie urbana, coincidiendo con las diferentes densidades poblacionales de las parroquias (alta - media - baja). En el siguiente periodo (2008), la situación se diversifica alcanzando niveles de aire muy contaminado (mayores a $300 \mu \mathrm{g} / \mathrm{m}^{3}$ ) y

1 Trabajo desarrollado en el marco de la línea de investigación Geodinámica Ambiental y Riesgos Naturales del Centro de Estudios Geográficos LUZ.

2 Magíster en Geografía mención docencia de la Universidad del Zulia. Investigador de proyectos adscritos al Centro de Estudios Geográficos de la Universidad del Zulia. Venezuela. eloyead@yahoo.com

3 Magíster en Psicología Educacional de la Universidad Rafael Urdaneta. Docente titular del Ministerio del Poder Popular para la Educación. Venezuela. hpceci@hotmail.com 
coincidiendo geográficamente con parroquias densamente pobladas.

Palabras clave: contaminación del aire, densidad poblacional, partículas suspendidas totales, sistemas de información geográfica.

\begin{abstract}
This study's aim was to make a space-time evaluation of the total suspended particles pollution in the metropolitan area parishes in Maracaibo, during the periods from 2001 to 2008. To achieve this goal, two data sources had been employed: the pollution TSP (annual average concentrations) recorded by the control and conservation of Maracaibo's Lake basin Institute (ICLAM) and demographic statistics (2001 Census). Considering Geographic Information Systems (GIS) spatial analysis methods were applied to the different layers. TSP contaminant in 2001 was moderate and evenly distributed in $98 \%$ of the urban surface, coinciding with the parishes' different population densities (high - medium - low); in the following scenario (2008), the situation is diversified and reached the heavily polluted air category (over $300 \mu \mathrm{g} /$ $\mathrm{m}^{3}$ ) coinciding these high levels of pollution in the parishes which recorded very high levels of population density.
\end{abstract}

Keywords: Air Pollution, Population density, Total suspended particles, Geographic Information Systems. 


\section{Introducción}

El incremento del consumo de combustibles fósiles en el ámbito mundial para suplir las necesidades del hombre contemporáneo, ha incidido en el aumento significativo de la contaminación atmosférica. Las evidencias son abundantes, una de las más notorias es la acelerada intensificación en la concentración de $\mathrm{CO}_{2}$, de la que tanto se hace mención en los medios de comunicación, debido a su relación directa con algunos fenómenos climáticos globales como el efecto invernadero. En efecto, para el 2009 , la presencia del referido gas en el aire ascendía a más de 32.000 millones de toneladas métricas (Banco Mundial, 2013). Sin embargo, existen otros contaminantes tan dañinos como este: el ozono $\left(\mathrm{O}_{3}\right)$, dióxido de nitrógeno $\left(\mathrm{NO}_{2}\right)$, dióxido de azufre $\left(\mathrm{SO}_{2}\right)$, monóxido de carbono $(\mathrm{CO})$, amoníaco $\left(\mathrm{NH}_{3}\right)$, partículas suspendidas totales (PST), etc. En esta oportunidad nos centraremos en estas últimas (de aquí en adelante PST), debido a que tienden a ser muy abundantes y de alta nocividad, ya que engloban todas las partículas sólidas y líquidas (polvo, polen, hollín, humo y pequeñas gotas) que se encuentran suspendidas en el aire, formando una mezcla de gran variedad de tamaños (desde grueso hasta fino y ultrafino). Su evaluación es importante porque en muchos casos pueden incluir material particulado que produce efectos perjudiciales en la salud, como las $\mathrm{PM}_{10}$ y $\mathrm{PM}_{2,5}$ (OMS, 2006).

Se puede afirmar que en muchos países en desarrollo, la contaminación en el aire ya genera secuelas tanto en la salud de los seres vivos, como daños en los materiales e infraestructuras urbanas, causando disconformidad en la población. En algunos países ya comienzan a asociarse los niveles de contaminación atmosférica con los índices de morbimortalidad de las poblaciones expuestas (Aranguez et al., 1999). Dicho problema se agudiza cuando hablamos de una dinámica atmosférica general, en que los contaminantes producidos en muchas partes del mundo generan efectos y consecuencias de índole planetario. Ratifican lo anterior, las estadísticas de la Organización Mundial de la Salud (2011), según las cuales se estima que la contaminación atmosférica causa alrededor de dos millones de muertes prematuras al año en todo el mundo. Así mismo, se calcula que la contaminación atmosférica urbana causa en todo el mundo 1,3 millones de muertes al año, que afectan de forma desproporcionada a quienes viven en países de ingresos medios (OMS, 2011).
Algunos estudios realizados, sugieren que determinadas fuentes emisoras de partículas en suspensión (en especial la generada por combustibles fósiles), están relacionadas con efectos perjudi- ciales para la salud (USEPA, 2013). En las grandes ciudades y urbes, es muy común en estos días que la población se encuentre en exposición a largo plazo a las partículas en suspensión; el efecto en la salud pública se refleja en el incre- mento de los índices de enfermedades del aparato respiratorio (insuficiencia respiratoria obstructiva, bronquitis cró- nica aislada o acompañada de enfisemas puros, cáncer de pulmón, enfermedades cardiovasculares, etc.). 
Según la información manejada por el Ministerio del Ambiente, en Venezuela la contaminación y degradación del aire provienen de diversas fuentes, entre las que destacan las emisiones emanadas de los vehículos automotores, actividades industriales, quema de basura, trituración y manipulación de materiales volátiles (MARN, 2001). Igualmente, se puede afirmar que la localización de las principales fuentes generadoras de la contaminación atmosférica y su área de influencia están, en la mayoría de los casos, ligadas al crecimiento de las urbes y sus zonas industriales.
Una evidencia de lo antes descrito, es el incremento en los últimos años del parque automotor, que ha contribuido a una mayor emisión de gases y, en consecuencia, a un empobrecimiento de la calidad del aire. El índice de calidad del aire con base en partículas IC-Aire $(\mathrm{P})^{4}$ para las principales ciudades del país, es un indicador que refleja como, para el periodo 2004-2008, la calidad se ha visto deteriorada pasando de una categoría buena a una regular-mala (Figura 1).

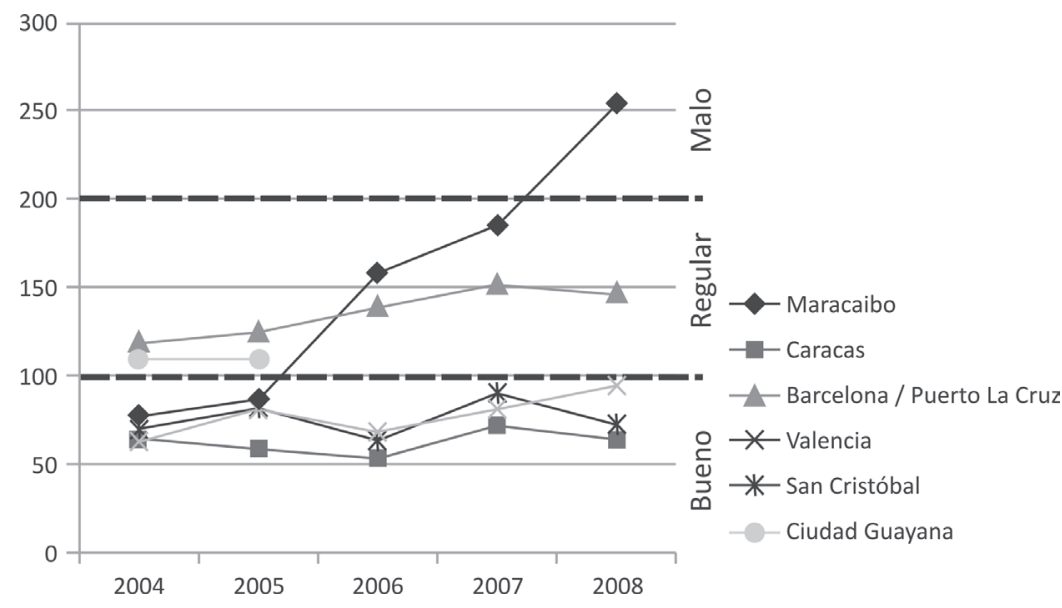

Figura 1. Índice de calidad del aire con base en partículas IC-Aire (P) ciudades de Venezuela.

Fuente: elaboración propia sobre cifras del Sistema de Indicadores y Estadísticas Nacionales para la Gestión del Ambiente SIENAGA (2013).

Según reflejan los datos de la Figura 1, en los últimos años la atmósfera de la ciudad de Maracaibo se ha convertido en la más contaminada del país, presentando una tasa de degradación de más del $300 \%$ para el periodo 2004-2008.

Nos encontramos ante una problemática de alta relevancia, que ya ha sido abor-
4 Para el Ministerio del Ambiente de Venezuela, el índice de calidad del aire con base en partículas IC-Aire (P), de una determinada zona, corresponderá al mayor de los valores obtenidos en el cálculo de los subíndices para cada uno de los contaminantes de partículas (partículas totales suspendidas -PTS- y material particulado con diámetro inferior a 10 micras - PM10). El índice consta de una escala numérica entre 0 y 500 , mientras más alto es el valor del IC-Aire, mayor es el nivel de contaminación atmosférica. El 100 en la escala corresponde a los límites máximos permitidos en la norma nacional de calidad del aire para los distintos contaminantes. 
dada en diversos estudios internacionales. En España, por ejemplo, un grupo de investigadores profundizó en esta línea (Moreno, 1995) y publicó ensayos teóricos sobre la medición de externalidades ambientales bajo un enfoque espacio-temporal: El ruido ambiental urbano en Madrid. Caracterización y evaluación cuantitativa de la población potencialmente afectable (Moreno \& Martínez, 2005); Justicia ambiental y contaminación atmosférica por dióxido de azufre en Madrid: análisis espaciotemporal y valoración con sistemas de información geográfica (Moreno \& Cañada, 2007); y uno de los trabajos donde se recoge gran parte de los avances en la materia, es Justicia ambiental. Del concepto a la aplicación en planificación y análisis de políticas territoriales, de Moreno (2010). También se han generado aportes metodológicos importantes: Interpolación espacial y visualización cartográfica para el análisis de la justicia ambiental: ensayo metodológico sobre la contaminación por partículas atmosféricas en Madrid (Cañada, Vidal \& Moreno, 2011).

En el caso concreto de Venezuela, los mayores antecedentes de este tipo de estudios pertenecen a disciplinas científicas tales como: ingeniería, química ambiental, biología, etc. Entre estos se encuentran trabajos como Estudio sobre los niveles de partículas suspendidas totales en la atmósfera de la ciudad de Maracaibo (Morales et al., 1995); también el artículo Partículas suspendidas totales y contenido de nitrato, cloruro y sulfato en el aire de dos zonas de Valencia (Martínez, 2003); y recientemente, el estudio Metales en
$P M_{10}$ y su dispersión en una zona de alto tráfico vehicular (Machado et al., 2007). Pero sólo en el año 2007 (Romero \& Montes) se lleva a cabo un primer ensayo sobre el estudio de la contaminación por PST en Maracaibo y su dimensión espacial, en un trabajo titulado Aportes geográficos interdisciplinarios en el estudio del problema de la contaminación del aire.

Como un aporte metodológico en esta área, el presente estudio hace una aproximación empírica al caso concreto de la ciudad de Maracaibo, que, como ya se mencionó, en Venezuela ha sido poco abordado desde la perspectiva del análisis espacial. El objeto perseguido fue realizar una evaluación espacio-temporal de la contaminación por partículas suspendidas totales en las parroquias del área metropolitana del municipio Maracaibo, con una dimensión diacrónica, pues se efectuó la valoración para dos períodos anuales 2001 y 2008, en los que se evidenciaron cambios tanto en la concentración del contaminante como en las densidades poblacionales de cada parroquia.

Desde hace ya más de treinta años, la geografía se dedica a trabajar dentro de la temática de los problemas ambientales, no sólo como un mero ejercicio académico que permita establecer un juicio de valor, sino que, tras la oportuna formación de juicios fundamentados, su aspiración última estriba en propiciar la eventual toma de decisiones y puesta en práctica de los planes o actuaciones pertinentes (Moreno, 2010). 
En consecuencia, se espera generar un aporte a partir de la revisión de algunos resultados de dos tipos de investigaciones; en primer lugar, las que se orientan a la evaluación de los impactos de la contaminación sobre la humanidad, formando parte de los estudios que establecen los niveles de vulnerabilidad, los cuales se desarrollan de forma multidisciplinar a distintas escalas espaciales y temporales, aunado a la proliferación de metodologías cuantitativas y cualitativas enfocadas a la elaboración de diagnósticos y evaluaciones sobre la vulnerabilidad ambiental y sociodemográfica (Sánchez \& Egea, 2009), y, en segundo lugar, los actuales trabajos sobre justicia ambiental que pretenden establecer una distribución espacio-temporal justa de los beneficios y cargas (Moreno, 2010).

\section{Descripción del lugar}

La unidad espacial seleccionada para la investigación, está conformada por la poligonal urbana del municipio Maracaibo, capital del estado Zulia, abarca un área de aproximadamente 189,19 $\mathrm{km}^{2}$ (o $18.919 h a$ ) y está localizada entre las siguientes coordenadas UTM este: $201.028,69 \mathrm{~m}$ a $217.807,03 \mathrm{~m}$ y norte $1.171 .513,67 \mathrm{~m}$ a $1.188 .643,12$ $\mathrm{m}$. Se ubica geográficamente en el noroeste del país, limitando al norte y oeste con la zona protectora de la ciudad de Maracaibo, la cual coincide con el límite urbano trazado por la Alcaldía del municipio Maracaibo. Es importante mencionar que a estos límites se le hicieron ciertas modificaciones que se explican más adelante. El límite este está definido por la línea de costa del lago de Maracaibo y al sur con el límite político territorial del municipio de San Francisco (Figura 2). El municipio Maracaibo, según la última ley políticoterritorial del Estado, está constituido por dieciocho parroquias, de las cuales diecisiete forman parte del área urbana, unas en su totalidad y las de la periferia parcialmente.

Maracaibo está emplazada en la planicie occidental del lago de Maracaibo, es la segunda ciudad más poblada de Venezuela y centro económico más importante del occidente del país, gracias al desarrollo de actividades administrativas vinculadas con la explotación y exportación del petróleo, así como de las actividades de gran intercambio comercial y servicios tanto a nivel nacional como internacional, en este último caso por su cercanía con las fronteras terrestres y marítimas.

\section{Metodología}

\subsection{Construcción de la base de datos geográfica}

En una primera etapa, se introdujeron modificaciones en los límites del área de estudio, con el objeto de actualizarlos, ya que la superficie urbanizada presentada en el plano oficial de la Alcaldía de Maracaibo no coincide con la realidad actual, debido a la expansión urbana hacia la zona periférica de la ciudad (principalmente hacia el oeste), como consecuencia de la conformación y ane- 

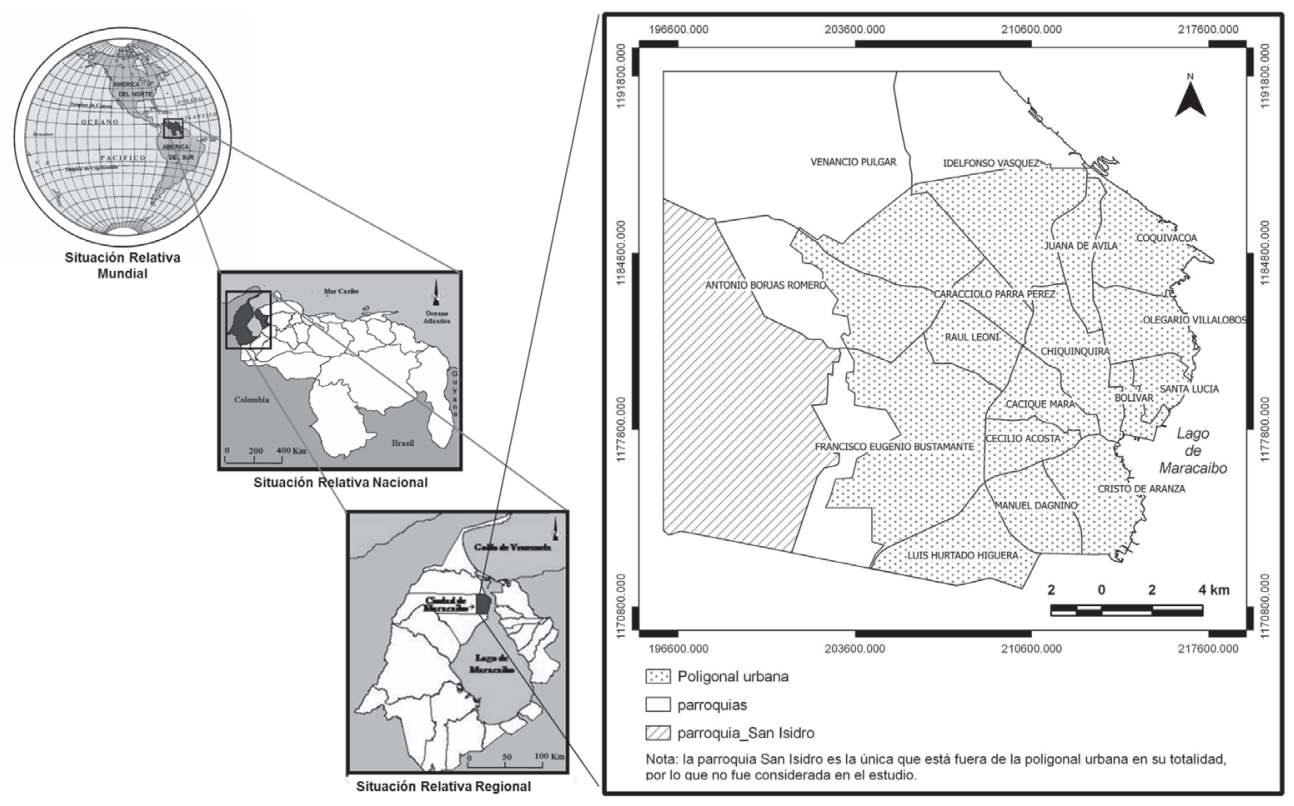

Figura 2. Situación relativa área urbana del municipio Maracaibo.

Fuente: elaboración propia a partir del plano de la Dirección de Catastro de la Alcaldía de Maracaibo (2001); Atlas de Venezuela en línea (1997).

xión de nuevos barrios y sectores. Para actualizar la poligonal urbana, se tuvo en consideración la forma del emplazamiento, basándose en el estudio visual del plano de la ciudad y de un mosaico de imágenes de satélite (previa corrección) obtenidas en la aplicación Google Earth versión 6.2. Sobre el mosaico se realizó posteriormente una digitalización vectorial ajustando el límite de la poligonal urbana. Se anota que las imágenes pertenecen a la plataforma espacial Digital Globe del año 2012.

En la siguiente etapa, se recolectaron datos correspondientes a las dos variables estudiadas y para los dos momentos específicos (2001 y 2008). Con respecto al estudio y análisis de la contami- nación del aire por PST, se partió de la selección de los sitios de muestreo, recolección y determinación analítica de las muestras, llevadas a cabo por el Instituto para el Control y la Conservación de la Cuenca del Lago de Maracaibo (ICLAM) durante el lapso de 1995 hasta 2008 (periodos de lluvia y sequia); sin embargo, para efectos del presente estudio, sólo se tomaron los datos correspondientes a los años 2001 y 2008. Para la selección del primer año (2001), el criterio que se asumió fue el de coincidencia con los datos del Censo de población y Vivienda 2001; en cuanto al segundo año (2008), el criterio fue determinado por la disponibilidad de los datos de PST con los que contaba el ICLAM para el momento del estudio. 
En cuanto a los sitios de muestreo, la referida institución (ICLAM) instaló cuatro estaciones bajo la denominación "Red de Medición de Calidad del Aire" (Red MECA). El procedimiento de recolección de las muestras, se llevó a cabo con cuatro muestreadores de aire de gran volumen repartidos dentro de la poligonal urbana de Maracaibo. Los métodos y técnicas implementados para la calibración de los equipos, la captación de las muestras y la determinación analítica, "fueron los establecidos por el Comité Venezolano de Normas Industriales (COVENIN), en los Métodos de Muestreo y Análisis de Aire, según Decreto $\mathrm{N}^{\circ} 638$, relativo a las Normas sobre Calidad del Aire y Control de la Contaminación Atmosférica" (ICLAM, 2009, p.15).

Los registros de PST de cada estación vienen expresados en microgramos por metro cúbico $\left(\mu \mathrm{g} / \mathrm{m}^{3}\right)$, las concentraciones (promedio anual) fueron digitalizadas en una hoja de cálculo Excel con sus respectivas coordenadas UTM (levantadas con receptor GPS), para posteriormente poder ser transferidas al SIG. En esta etapa se comenzó a hacer uso del software QGIS versión 2.0.

Por otra parte, para la variable "distribución de la densidad poblacional urbana por parroquias", se utilizaron las estadísticas demográficas correspondientes a las diecisiete parroquias ubicadas dentro del área, tomando los datos correspondientes a los años 2001-2008, levantados por el Censo de Población y Vivienda del 2001, y los correspondientes al 2008, proyectados por el Instituto Nacional de Estadística (INE), Dirección Estadal Zulia.
Para el desarrollo de la base de datos de la variable densidad poblacional, se inició con la digitalización de los polígonos (parroquias), utilizando como base cartográfica el Plano de la Dirección de Catastro de la Alcaldía de Maracaibo, a escala 1: 20.000 .

\subsection{Procesamiento de los datos}

Una vez ingresados los datos puntuales de PST al software QGIS, se procedió a aplicar la herramienta de cuadrícula (interpolación), con el objeto de modelar el patrón espacial del contaminante elegido (PST), y así obtener mapas de superficie en los dos años 2001 y 2008. Se seleccionó el interpolador espacial distancia inversa a una potencia (Inverse Distance to a Power), entendiendo como interpolación espacial o de superficie "un procedimiento que permite calcular el valor de una variable en una posición del espacio (punto no muestral, con un valor estimado), conociendo los valores de esa variable en otra posición del espacio (puntos muestrales con valores reales)" (Bosque, 1997, p. 375).

Se ajustaron los parámetros de interpolación, del área y ángulo de búsqueda. En este caso existe una influencia direccional en el peso de los datos, que está dada por los efectos de los vientos predominantes, los cuales van en dirección nor-noreste $\left(22,5^{\circ}\right.$ aproximadamente $)$ para el área de Maracaibo (Figura 3). Por eso la forma que debe adoptar la búsqueda de la vecindad es de una elipse, donde el eje mayor debe estar paralelo al fenómeno considerado (viento). 


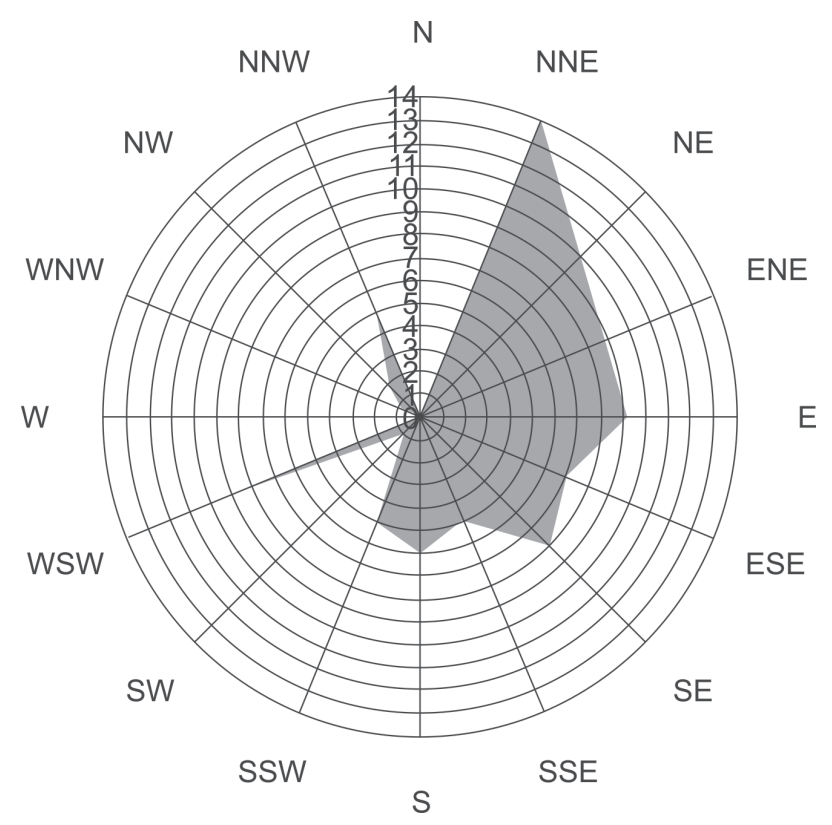

Figura 3. Tendencia prevaleciente de la dirección del viento para Maracaibo.

Fuente: Estación Meteorológica Maracaibo-La Chinita (2013).

Como resultado del proceso anterior se generaron dos imágenes, para lo cual se definió un marco de escala de las unidades espaciales más pequeñas (píxeles) con las siguientes coordenadas UTM extremas: (Uso 19, Zona P) este: $\mathrm{X}_{\min }=$ $196.000 \mathrm{mts}$. $X_{\max }=218.000 \mathrm{mts}$. y por el norte: $\mathrm{Y}_{\min }=1.171 .300 \mathrm{mts} . \mathrm{Y}_{\max }=$ 1.192.000 mts., obteniendo así una resolución por píxel de 25 x 25 metros en el Datum: sistema geodésico provisional Sudamérica 56', lo que garantiza una compatibilidad en las capas y facilita los posteriores tratamientos analíticos.

Una vez exportadas/importadas las capas, se continuó con los procesos de

$5 \quad$ Estadísticas basadas en observaciones diarias tomadas entre 7 am y 7 pm hora local. análisis espaciales en el software Idrisi Kilimanjaro, procediendo al análisis por generalización-reclasificación de las imágenes. En el caso de los rangos de concentraciones de PST, se establecieron los intervalos o categorías con fundamento en las Normas sobre Calidad del Aire y Control de la Contaminación Atmosférica, capítulo I, artículo 5, pertenecientes al Régimen Venezolano de Legislación Ambiental, que clasifica las concentraciones de PST en cuatro rangos con base en promedios anuales. (Tabla 1)

En cuanto a la variable poblacional, al no existir un criterio oficial en que basar la clasificación, se asumió un indicador de densidad poblacional y un método estadístico; el primero de ellos 
Tabla 1. Niveles y rangos de PST

\begin{tabular}{|c|c|c|}
\hline $\mathbf{N}^{\mathbf{0}}$ & Niveles de calidad del aire & Rangos de PST $\left(\boldsymbol{\mu g} / \mathbf{m}^{\mathbf{3}}\right)$ \\
\hline 1 & Aire limpio & $<75$ \\
\hline 2 & Aire moderadamente contaminado & $75-200$ \\
\hline 3 & Aire altamente contaminado & $201-300$ \\
\hline 4 & Aire muy contaminado & $>300$ \\
\hline
\end{tabular}

Fuente: Normas sobre calidad del aire y control de la contaminación atmosférica, capítulo I artículo 5 (1995).

está referido al cálculo de densidad de población (habitantes / $h a$ ), para lo cual se utilizó la herramienta calculador de campos del software QGIS; una vez calculada la densidad poblacional para cada parroquia, se procedió a agruparlas en intervalos de clase, a través del método de intervalos por cuantiles, el cual consiste en dividir el rango de valores en cuatro clases, cada una de ellas con igual número de elementos (parroquias). Con esto se trató de maximizar la información que se transmite y de aprovechar lo mejor posible la variable visual empleada (Tabla 2), estos intervalos se aplicaron a los dos años de estudio.

Tabla 2. Niveles y rangos de densidad de población

\begin{tabular}{|c|c|c|}
\hline $\mathbf{N}^{\mathbf{0}}$ & Niveles & $\begin{array}{c}\text { Rangos } \\
\text { (Habitantes } / \mathbf{h a})\end{array}$ \\
\hline 1 & Bajo & $44,45-57,49$ \\
\hline 2 & Medio & $57,49-70,41$ \\
\hline 3 & Alto & $70,41-81,38$ \\
\hline 4 & Muy alto & $81,38-113,36$ \\
\hline
\end{tabular}

Fuente: elaboración propia.

Una vez clasificadas las capas para ambas variables, se hizo un recorte de las capas mediante el módulo OVERLAY del software Idrisi Kilimanjaro, con el objeto de reducir el área de estudio a la poligonal definida en este caso como urbana. De esta manera, las medidas de superficie (áreas en $h a$ ) serían más precisas. Por último, por medio del módulo CROSSTAB, se aplicó la clasificación cruzada que muestra la combinación de zonas de PST y densidades poblacionales, generando las tablas con valores únicos en píxeles para cada combina- ción, que posteriormente se llevaron a unidades en $h a$ por cada categoría de la combinación; así mismo esta operación deriva las estadísticas de similitud entre las capas de entrada (V de Cramer).

\section{Resultados y discusión}

Los resultados y su discusión se estructuraron en tres partes; la primera formada por los resultados sobre la distribución espacio-temporal de las partículas 
suspendidas totales; la segunda, la distribución espacio-temporal de la densidad de población, y, por último, la combinación de niveles de PST con niveles de densidad poblacional por parroquias.

\subsection{Distribución espacio-temporal de las partículas suspendidas totales en la ciudad de Maracaibo}

Según los informes técnicos del ICLAM, la presencia de PST en la atmósfera de la ciudad de Maracaibo está asociada con las emisiones del parque industrial, el tráfico automotor y suelos desprovistos de vegetación (ICLAM, 2009); así mismo, otra de las fuentes de gran cantidad de material particulado es la industria de la construcción, que, en el caso concreto de Maracaibo, presenta en la actualidad un franco crecimiento, debido a la construcción de una cantidad importante de nuevos conjuntos residenciales (edificios, villas) y sectores populares. Al evaluar la distribución espacial de la contaminación por PST en Maracaibo para el año 2001 (Figura 4), se evidencian varios hechos.

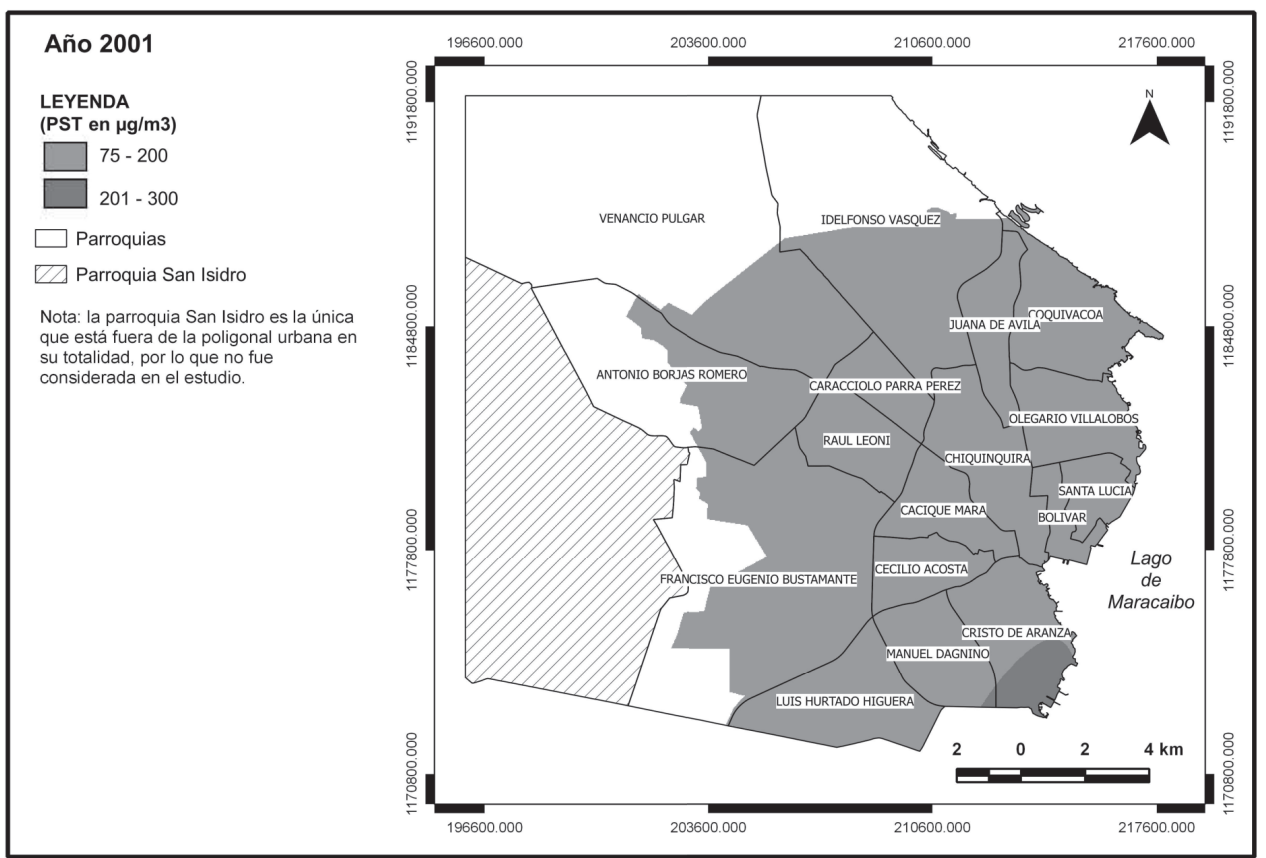

Figura 4. Concentraciones media anual 2001 de PST en la atmósfera de Maracaibo.

Fuente: elaboración propia con cifras del ICLAM (2009).

De los cuatro niveles de calidad del aire establecidos por la legislación ambiental venezolana, sólo se reflejan dos, aire moderadamente contaminado y aire altamente contaminado.
Las mayores concentraciones de PST, con valores iguales y superiores a 201 $\mu \mathrm{g} / \mathrm{m}^{3}$ (aire altamente contaminado), se localizan en una pequeña zona al sureste de la ciudad, afectando parcialmente 
el territorio de las parroquias Cristo de Aranza y Manuel Dagnino. Como se ha demostrado en otras investigaciones, esta zona de la ciudad está bajo la influencia de la planta termoeléctrica Ramón Laguna (Morales et al., 1995). Las concentraciones más bajas, por debajo de $200 \mu \mathrm{g} / \mathrm{m}^{3}$ hasta $75 \mu \mathrm{g} / \mathrm{m}^{3}$, se localizan en casi la totalidad del área urbana.
La observación del modelo interpolado para el año 2008 (Figura 5), revela un patrón espacial distinto al anterior, con valores más elevados, apareciendo para este año un nuevo nivel (aire muy contaminado).

Las mayores concentraciones de PST, superiores en esta oportunidad a 300

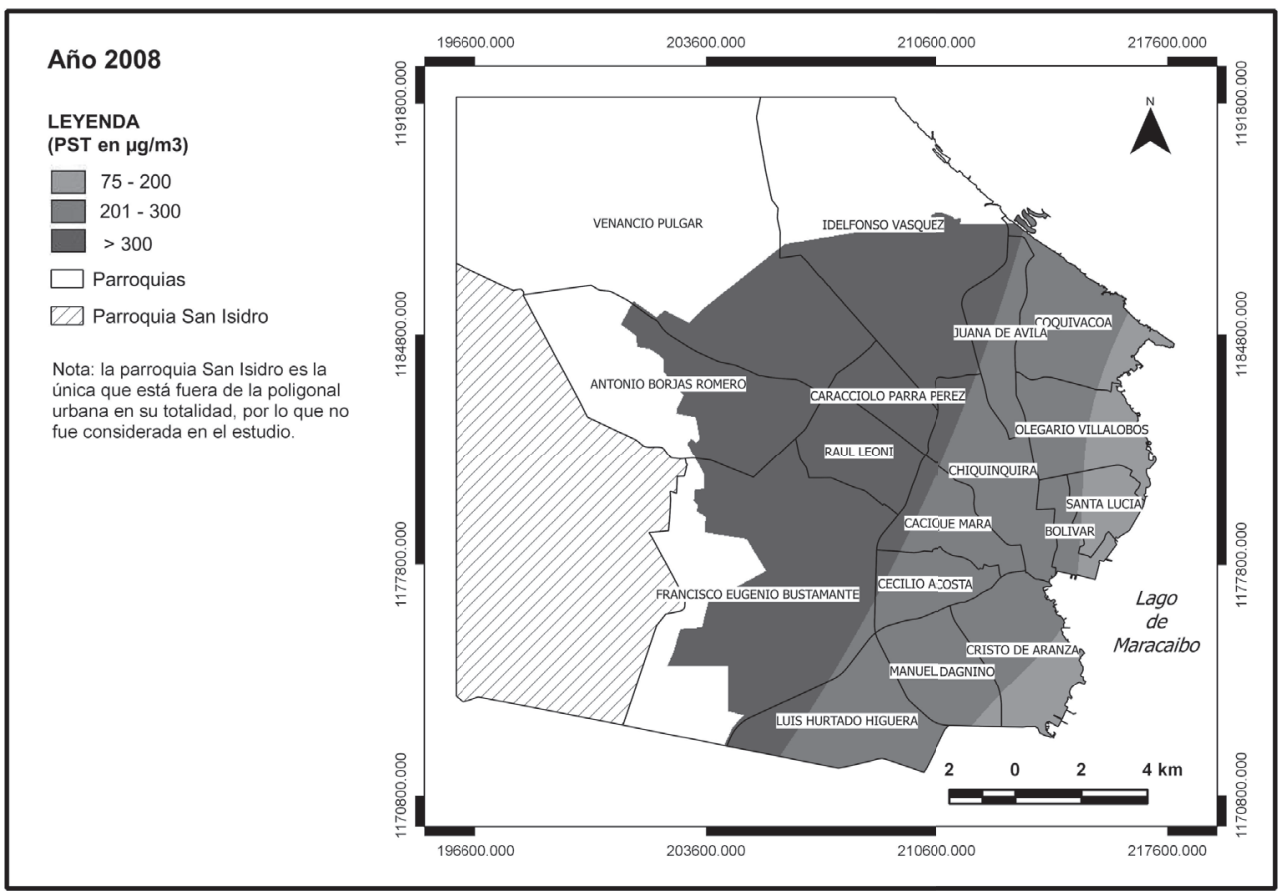

Figura 5. Concentraciones media anual 2008 de PST en la atmósfera de Maracaibo.

Fuente: elaboración propia con cifras del ICLAM (2009).

$\mu \mathrm{g} / \mathrm{m}^{3}$ hasta $444 \mu \mathrm{g} / \mathrm{m}^{3}$ (aire muy contaminado), representan los valores más altos registrados (ICLAM, 2009). Estas áreas se localizan en el centro-oeste y noroeste de la zona estudiada, afectando las parroquias Idelfonso Vásquez, Venancio Pulgar, Antonio Borjas Romero, Francisco Eugenio Bustamante y parcialmente la superficie de las parroquias
Juana de Ávila, Chiquinquirá, Cacique Mara, Cecilio Acosta y Luis Hurtado Higuera. El incremento del contaminante para este periodo se debe, entre otras causas, al aumento del parque automotor en la ciudad.

Las concentraciones intermedias entre 201 y $300 \mu \mathrm{g} / \mathrm{m}^{3}$ (aire altamente conta- 
minado), se ubican para este año en una amplia franja con sentido noreste-suroeste, abarcando parcialmente los territorio de las parroquias Coquivacoa, Juana de Ávila, Olegario Villalobos, Chiquinquirá, Bolívar, Cacique Mara, Cecilio Acosta, Cristo de Aranza, Manuel Dagnino, y Luis Hurtado Higuera.

Las áreas menos contaminadas se localizan en el centro-este y al sureste del municipio, comprendiendo parcialmente el espacio de las parroquias Coquivacoa, Olegario Villalobos, Santa Lucia, Bolívar, Cristo de Aranza y Manuel Dagnino.

En cuanto a los cambios más destacados entre las dos situaciones 2001 y 2008, se observa en primer lugar, que para el año 2008 existe una nueva categoría con mayor nivel de contaminación por PST (aire muy contaminado), lo que indica que en el transcurso de ocho años la degradación de la calidad del aire es acelerada. Como ya se mencionó, las causas están asociadas al incremento del tráfico vehicular y fuentes de generación eléctrica (Machado et al., 2007). Al comparar las áreas de cada nivel de calidad del aire, se observa que, mientras en el 2001, la mayor zona está ocupada por el aire moderadamente contaminado (98 $\%$ ), para el año 2008, la mayor área (54 $\%$ ) la ocupa la categoría de aire muy contaminado, seguida por aire altamente contaminado, que representa un $37 \%$ (Figura 6).

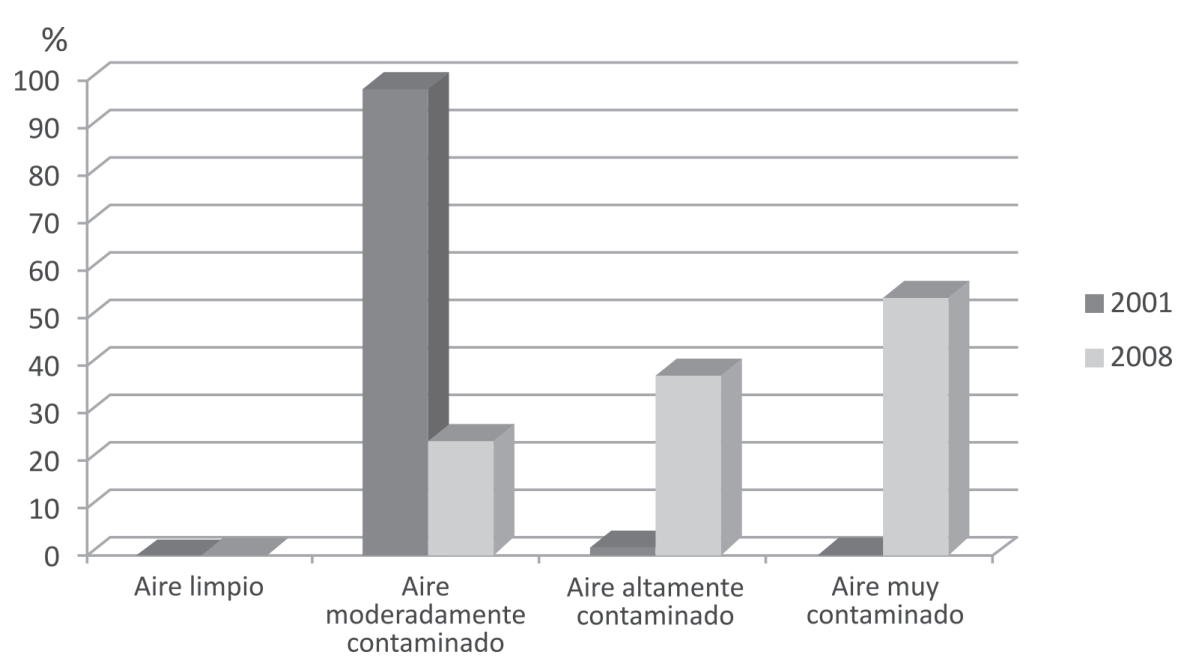

Figura 6. Porcentaje de superficie urbana por cada nivel de contaminación por PST.

Fuente: elaboración en base a cálculos propios.

Como balance general de lo antes expuesto, se puede decir que entre las diferencias encontradas en las situaciones interpoladas, destaca en primer lugar el fuerte incremento de las PST en la urbe Marabina, con valores máximos que pasaron de 259 a $444 \mu \mathrm{g} / \mathrm{m}^{3}$ en menos de una década; en segundo lugar está el 
hecho de que las diferencias intraurbanas en la presencia del contaminante se hacen mayores.

\subsection{Distribución espacio-temporal de la densidad de población en la ciudad de Maracaibo}

En la Figura 7 se observa el mapa correspondiente a la distribución de las densidades de población urbana por parroquias en Maracaibo para el año 2001. Las parroquias con densidades muy altas y altas se ubican así: con niveles de densidades muy altas se localizan al centro-norte las parroquias Caracciolo Parra Pérez y Juana de Ávila; con igual densidad al centro-sur del municipio, se ubican las parroquias Cecilio Acosta y Manuel Dagnino; en una línea con dirección noroeste-sureste se localizan las parroquias Raúl Leoni, Cacique Mara y Cristo de Aranza, con niveles altos de densidad poblacional; y aislada del grupo anterior, al este, la parroquia Santa Lucia.

Por otra parte, las áreas con valores intermedios de densidad se mostraban así: ocupando la zona este de la ciudad, las parroquias Coquivacoa, Olegario Villalobos y Bolívar; al noroeste, Venancio Pulgar. Las bajas densidades se distribuyen en dos grupos, el primero al cen-

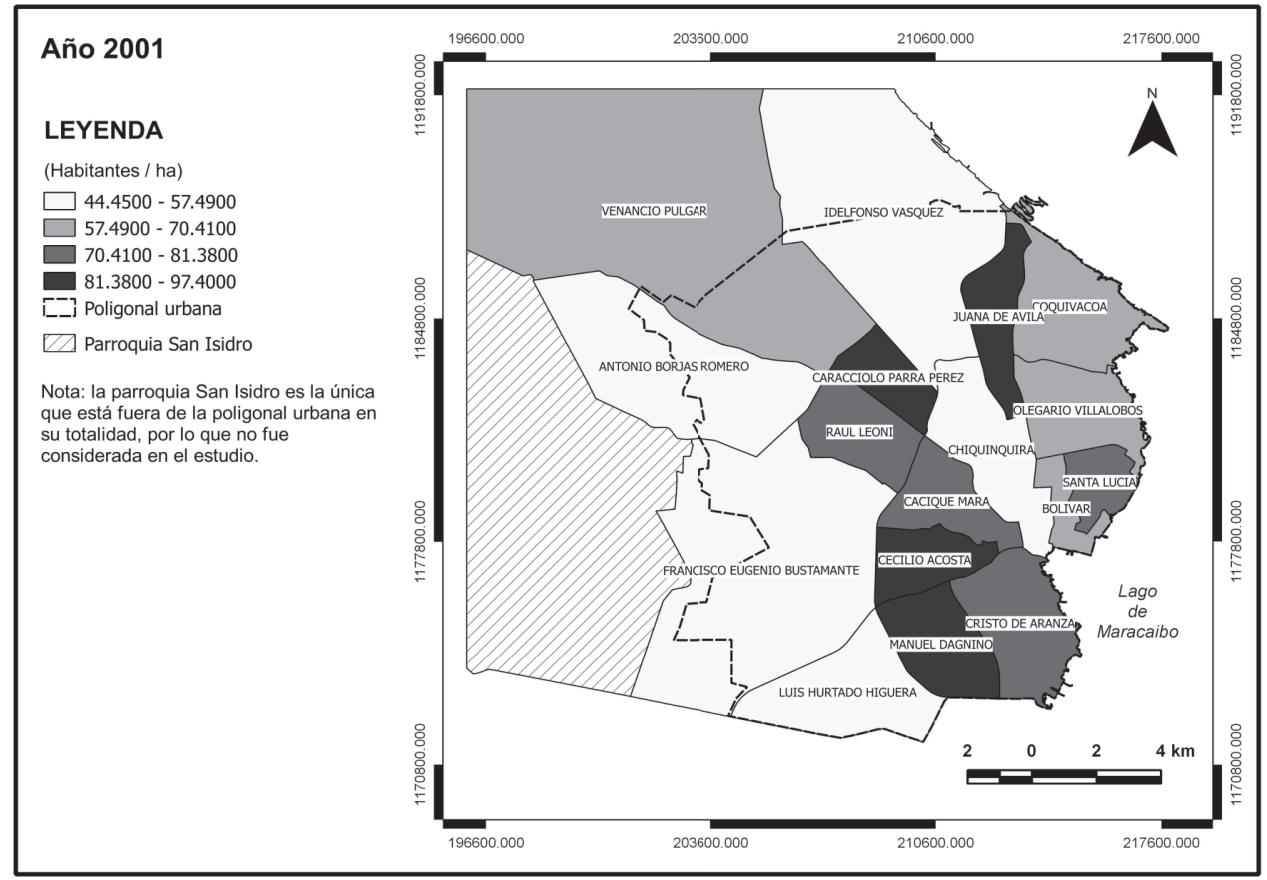

Figura 7. Distribución espacial de la densidad de población urbana por parroquias de Maracaibo 2001.

Fuente: elaboración propia a partir del plano de la Dirección de Catastro de la Alcaldía de Maracaibo (2001) y cifras del INE (2004). 
tro-norte conformado por las parroquias Chiquinquirá e Idelfonso Vásquez, y el segundo al oeste, por Antonio Borjas Romero y Francisco Eugenio Bustamante, $\mathrm{y}$ al sur, por Luis Hurtado Higuera.

En el año 2008 (Figura 8), las parroquias con muy alta densidad poblacional se distribuyen en tres grupos: al centro-este, las parroquias Bolívar y Santa Lucia, que forman parte del núcleo originario de la ciudad; un segundo grupo lo conforma un bloque de parroquias con orientación noroeste-sureste, Caracciolo Parra Pérez, Raúl Leoni, Cacique Mara, Cecilio Acosta, Manuel Dagnino y Cristo de Aranza; por último y de forma aislada de las anteriores parroquias, está al noreste Juana de Ávila. Por otra parte, las parroquias con densidad poblacional alta, se distribuyen en dos grupos: al noroeste, las parroquias Venancio Pulgar y Antonio Borjas Romero, y el segundo está conformado por Olegario Villalobos al este. Las parroquias con densidades intermedias se ubican como sigue: Coquivacoa al noreste; Idelfonso Vásquez al norte; Luis Hurtado Higuera al sur. Para finalizar, las parroquias con baja densidad poblacional: Chiquinquirá al centro de la poligonal urbana, y Francisco Eugenio Bustamante al suroeste.

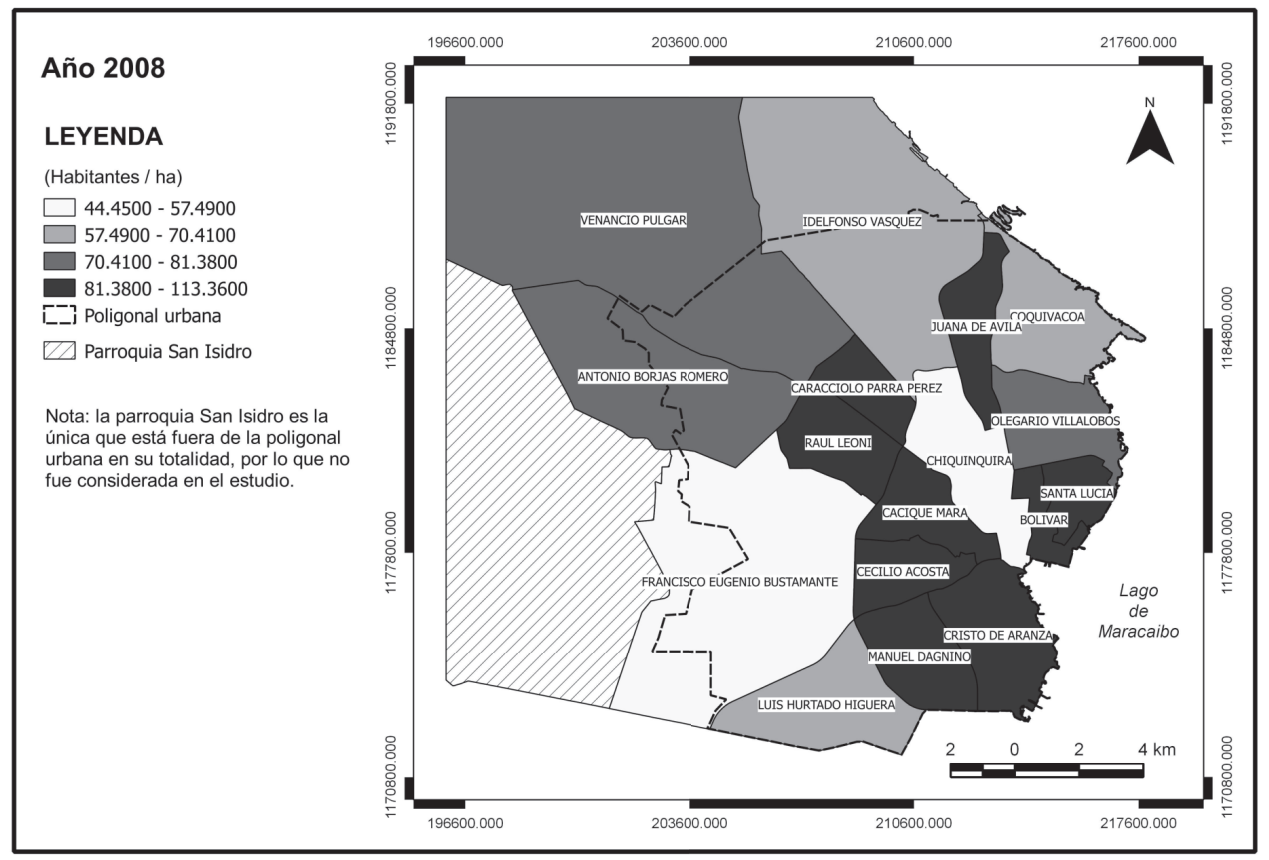

Figura 8. Distribución espacial de la densidad de población urbana por parroquias de Maracaibo 2008.

Fuente: elaboración propia a partir del plano de la Dirección de Catastro de la alcaldía de Maracaibo (2001) y cifras proyectadas del INE (2004). 
Asumiendo el patrón de crecimiento radial que presenta la ciudad desde la década del setenta (Rodríguez et al., 1982), se puede dividir la poligonal urbana en dos anillos concéntricos con centro en la parroquia Bolívar por ser del núcleo originario, y así derivar el siguiente análisis comparativo:

Para el año 2001 se comienza a visualizar un primer anillo con densidades poblacionales altas y muy altas en las parroquias: Juana de Ávila, Caracciolo Parra Pérez, Raúl Leoni, Cacique Mara, Cecilio Acosta, Manuel Dagnino y Cristo de Aranza. Esta distribución se explica a lo largo de la evolución de ciudad, ya que estas parroquias formaban parte de los límites de la ciudad, pasada la primera mitad del siglo XX, y ya para finales de siglo, se han consolidado muchas de sus barriadas y sectores, por eso en 2001, las densidades empiezan a aumentar considerablemente. En el segundo anillo se observa un caso contrario al anterior, debido a que son las parro- quias de más reciente ocupación (Idelfonso Vásquez, Venancio Pulgar, Antonio Borjas Romero, Francisco Eugenio Bustamante y Luis Hurtado Higuera).

Para el año 2008, las parroquias ubicadas en el primer anillo pasaron a formar parte de la categoría muy alta densidad poblacional (Juana de Ávila, Caracciolo Parra Pérez, Raúl Leoni, Cacique Mara, Cecilio Acosta, Manuel Dagnino y Cristo de Aranza). Y se puede observar como las parroquias del segundo anillo (Idelfonso Vásquez, Venancio Pulgar, Antonio Borjas Romero y Luis Hurtado Higuera) para el 2008, comienzan a pasar de la categoría media a la de alta densidad poblacional.

Otra interpretación que se puede derivar es a partir de la superficie ocupada por cada nivel de densidad poblacional (Figura 9). En 2001, más del $47 \%$ de la superficie urbana lo ocupaban las parroquias con baja densidad poblacional, seguidas en porcentaje en orden decre-

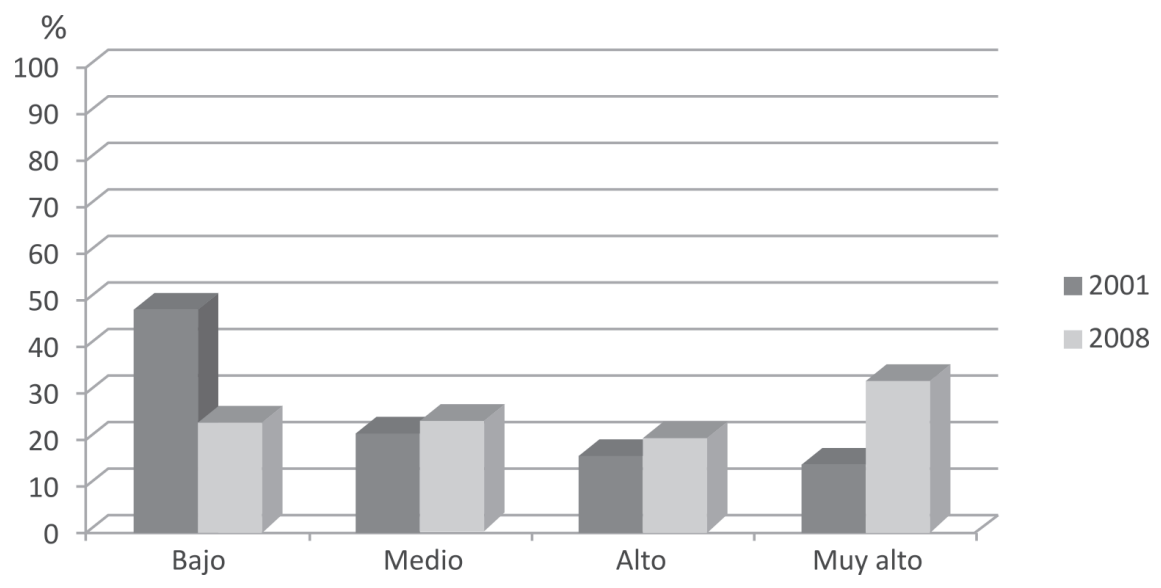

Figura 9. Porcentaje de superficie urbana por cada nivel de densidad poblacional.

Fuente: elaboración con base en cálculos propios. 
ciente en superficie y creciente en densidad, media densidad (21\%), alta densidad (16\%) y muy alta densidad (14\%).

Para el 2008, se observa como el patrón anterior se comienza a invertir, pasando a ocupar el mayor porcentaje de superficies urbanas las parroquias más densamente pobladas (categoría muy alto 32 $\%$ ), seguido por medio (24\%), bajo (23 $\%)$ y alto (19 \%).

\subsection{Combinación de niveles de PST con niveles de densidad poblacional por parroquias}

En la Tabla 3 se puede examinar la relación entre contaminación por PST y los niveles de densidad de población; en esta se describe la distribución del espacio ocupado por cada nivel de población según niveles de contaminación.

Tabla 3. Superficie (ha) ocupada por cada nivel de densidad poblacional 2001según el nivel de PST en 2001

\begin{tabular}{|c|r|r|r|}
\hline \multirow{2}{*}{$\begin{array}{c}\text { Niveles de densidad } \\
\text { poblacional }\end{array}$} & $\begin{array}{c}|c| \\
\text { Niveles de PST } \\
\text { moderadamente } \\
\text { contaminado }\end{array}$ & $\begin{array}{c}\text { Aire altamente } \\
\text { contaminado }\end{array}$ & Total \\
\hline Baja & 9063 & 0 & 9063 \\
\hline Media & 3994 & 0 & 3994 \\
\hline Alta & 2783 & 358 & 3141 \\
\hline Muy alta & 2702 & 17 & 2719 \\
\hline Total & 18543 & 376 & 45540 \\
\hline
\end{tabular}

Fuente: elaboración con base en cálculos propios.

Partiendo de los niveles de calidad del aire, el nivel de aire altamente contaminado $\left(201-300 \mu \mathrm{g} / \mathrm{m}^{3}\right)$, coincide en la mayor parte de la superficie, con los niveles altos de densidad de población, superponiéndose en 358 ha de la totalidad urbana.

En el nivel de aire moderadamente contaminado $\left(75-200 \mu \mathrm{g} / \mathrm{m}^{3}\right)$, la mayor coincidencia es con niveles bajos de densidad poblacional, superponiéndose en 9063 ha. Los restantes niveles de densidad de población (media, alta y muy alta) se cruzan en 9479 ha con la categoría de aire moderadamente contaminado.
El coeficiente de asociación V de Cramer nos permite resumir la relación de las categorías cualitativas de ambas variables (niveles). Se interpreta de la siguiente manera: en cualquier tabla, independientemente de la cantidad de filas y columnas, $\mathrm{V}$ de Cramer está entre $0 \mathrm{y}$ 1 , dado que su valor siempre es un número positivo, no se pueden hacer afirmaciones acerca de la dirección de la relación. Cuando V de Cramer es igual o superior a 0,6 , se considera que hay una correlación relativamente intensa entre $\mathrm{X}$ y $\mathrm{Y}$, en este caso es de 0,7385 entre ambas variables. 
La situación en la ciudad, ocho años después de la ya descrita que se muestra en la Tabla 4, el nivel de contaminación por PST es más intenso, el aire muy contaminado ( $>300 \mu \mathrm{g} /$ $\mathrm{m}^{3}$ ) posee una notable coincidencia con el alto nivel de densidad poblacional (2734 ha). Los niveles de aire altamente contaminado (201-300 $\mu \mathrm{g} /$ $\mathrm{m}^{3}$ ), tienden a ser más altos en los niveles más densamente poblados, con una superficie de coincidencia de 3414 ha. En el nivel de aire moderadamente contaminado $\left(75-200 \mu \mathrm{g} / \mathrm{m}^{3}\right)$, la mayor coincidencia es con los niveles muy altos de densidad poblacional (947 ha).
El coeficiente de asociación $\mathrm{V}$ de Cramer para este año (2008), aunque en menor medida que el anterior, sigue denotando una relación relativamente intensa entre ambas variables $(0,6302)$. En esta situación es notorio el cruce entre altos niveles de contaminación con altos niveles de densidad de población.

En resumen, para este año se confirma la existencia de mayor coincidencia entre contaminación por PST sobre zonas más densamente habitadas, mientras que las áreas menos pobladas cuentan con una atmósfera con moderada contaminación; resultados que pueden mostrar un notable deterioro de la calidad del aire.

Tabla 4. Superficie (ha) ocupada por cada nivel de densidad poblacional según el nivel de PST en 2008

\begin{tabular}{|c|r|r|r|r|}
\hline \multirow{2}{*}{$\begin{array}{c}\text { Niveles de densidad } \\
\text { poblacional }\end{array}$} & \multicolumn{4}{|c|}{ Niveles de PST } \\
\cline { 2 - 5 } & $\begin{array}{c}\text { Aire } \\
\text { moderadamente } \\
\text { contaminado }\end{array}$ & $\begin{array}{c}\text { Aire altamente } \\
\text { contaminado }\end{array}$ & $\begin{array}{c}\text { Aire muy } \\
\text { contaminado }\end{array}$ & \multirow{2}{*}{ Total } \\
\hline Baja & 0 & 1077 & 3420 & 4497 \\
\hline Media & 190 & 2103 & 2277 & 4570 \\
\hline Alta & 402 & 548 & 2734 & 3684 \\
\hline Muy alta & 947 & 3414 & 1805 & 6166 \\
\hline Total & 1540 & 7143 & 10236 & 45540 \\
\hline \multicolumn{4}{|c|}{ V de Cramer $=0,6300$} \\
\hline
\end{tabular}

Fuente: elaboración con base en cálculos propios.

\section{Conclusiones}

La sociedad global, y muy especialmente las sociedades científicas, ya no pueden estar a espaldas del inminente crecimiento de los efectos y daños en el bienestar de la salud pública ocasionados por la contaminación, en muchos casos como consecuencia de las acciones tomadas por los seres humanos durante décadas de apatía y políticas poco efectivas, lo que conlleva una mayor vulnerabilidad ante los agentes que enrarecen nuestro entorno.

Al medir la calidad del aire y cruzar sus valores con las estadísticas sociodemográficas, se trata de dar una aproximación en una doble vertiente a los posibles niveles de vulnerabilidad a los que se encuentra sometida la población y la relación entre incremento de la 
densidad poblacional e incremento de los contaminantes. Las grandes urbes y urbes intermedias en crecimiento constante, como el caso aquí tratado, cada vez están más expuestas por mayores periodos a situaciones de contaminación de diferentes tipos y volúmenes. El panorama en la ciudad de Maracaibo no es positivo, si se evalúan los modelos, para el 2001 la categoría de aire moderadamente contaminado ocupaba un $98 \%$ de la superficie de la ciudad, mientras que para 2008 se tiene más de un $54 \%$ del área con aire muy contaminado.

El patrón espacial de la calidad del aire para el 2001, se muestra uniforme en el espacio urbano, con niveles de contaminación moderados cubriendo casi todos los niveles de densidad poblacional (bajos-medios-altos). El patrón espacial en el 2008, difiere notablemente de la situación anterior; en primer lugar, porque se incrementa el nivel de PST, y en segundo lugar, porque hay grandes superficies donde coinciden niveles altos de densidad poblacional con niveles muy altos de contaminación.

Es necesaria la creación de un sistema integrado de vigilancia permanente con una cantidad adecuada de estaciones, que registren en tiempo cuasi real y permitan el monitoreo constante de los contaminantes del aire (químicos y biológicos), en las áreas urbanas como la ciudad de Maracaibo. Dicho sistema debe estar complementado por un SIG que integre las variables de contaminación, atmosféricas, socioeconómicas y epidemiológicas, para así poder generar predicciones mediante las evaluaciones espacio-temporales. Todo esto, sin duda, permitirá posteriormente soportar la toma de decisiones y los planes de prevención y mejoramiento de la calidad de vida.

Ante el acelerado crecimiento de la población en el municipio estudiado, es apremiante la creación de planes de ordenación de los espacios urbanos, que tomen en cuenta las evaluaciones ambientales y los tipos de usos del suelo, al momento de autorizar nuevos desarrollos habitacionales, industriales y comerciales. Por otra parte, también es imperativo generar políticas de educación ambiental acompañadas de materiales instruccionales adecuados, que propicien en la población una cultura con respecto a las fuentes de contaminación y sus efectos; por cierto, las actuales tecnologías de la información geográfica permiten producir materiales visuales que facilitan el entendimiento de fenómenos antrópicos y naturales a un público incluso no especializado.

\section{Agradecimientos}

Al Instituto para la Conservación de la Cuenca del Lago de Maracaibo (ICLAM), específicamente a la Gerencia de Investigación Ambiental, División Calidad del Aire, por los datos suministrados para la ejecución de la presente investigación. 


\section{Literatura citada}

Aránguez, E., Ordoñez, J., Serrano, J., Aragonés, N., Fernández, R., Gandarillas, A. \& Galán, I. (1999). Contaminantes atmosféricos y su vigilancia. Revista Española de Salud pública, 73(2), 123-132.

Banco Mundial. (2013). Emisiones de $\mathrm{CO}_{2}$. Recuperado de http://wdi.worldbank. org/table/3.8

Bosque, J. (1997). Sistemas de información geográfica. (2a ed.). Madrid: Rialp.

Cañada, R., Vidal, M. \& Moreno, A. (2011). Interpolación espacial y visualización cartográfica para el análisis de la justicia ambiental: ensayo metodológico sobre la contaminación por partículas atmosféricas en Madrid. GeoFocus, 11, 118-154. Recuperado de www.geo-focus.org

Castro, C. (2001). Régimen venezolano de legislación ambiental. Caracas: Legis.

Clark Labs. (2003). Idrisi Kilimanjaro. Clark University. Licencia del Centro de Estudios Geográficos de la Universidad del Zulia.

Comisión Venezolana de Normas Industriales. (1995). Control de la contaminación atmosférica. Gaceta Oficial de la República de Venezuela, (4899).

Dirección de Catastro de la Alcaldía de Maracaibo. (2001). Plano de Maracaibo. Maracaibo, Venezuela.

Estación Meteorológica de Maracaibo La Chinita. (2013). Datos dirección del viento. Recuperado de http://es.windfinder.com/windstats/windstatistic_maracaibo-la_chinita.htm

Instituto para el Control y la Conservación de la Cuenca del Lago de Maracaibo. (2009). Calidad de aire en la ciudad de Maracaibo 1995-2008. Informe del estado y tendencia de la contaminación atmosférica. Maracaibo, Venezuela: Gerencia de Investigación Ambiental, División Calidad de Aire.

Instituto Nacional de Estadística. (2004). Estadísticas de población del estado Zulia. Venezuela: Ministerio del Poder Popular para la Planificación y Desarrollo: Dirección Estadal.

Machado, A., Velázquez, H., García, N., García, C., Acosta, L., Córdova, A. \& Linares, M. (2007). Metales en $\mathrm{PM}_{10} \mathrm{y}$ su dispersión en una zona de alto tráfico vehicular. Revista de ciencia y tecnología de Americe Interciencia, 32 (5). Caracas. 
Martínez, Y. (2003). Partículas suspendidas totales y contenido de nitrato, cloruro y sulfato en el aire de dos zonas de Valencia. Trabajo de ascenso. Facultad de Ingeniería, Universidad de Carabobo.

Ministerio del Ambiente y de los Recursos Naturales. (2001). Problemas ambientales en Venezuela. Caracas, Venezuela: MARN.

Ministerio del Poder Popular para el Ambiente (2013) Sistema de indicadores y estadísticas nacionales para la gestión del ambiente. Recuperado de http://www. minamb.gob.ve/files/planificacion-y-presupuesto/IndicadoresAmbientales.htm

Morales, A., de Borrego, B., de Nava, M., Velásquez, H., Chirinos, M. \& Vacca, V. (1995). Estudio sobre los niveles de partículas suspendidas totales en la atmósfera de la ciudad de Maracaibo. Revista Técnica, 18 (1), 31-141.

Moreno, A. (1995). La medición de externalidades ambientales: un enfoque espacio-temporal. Anales de Geografía, 15, 485-496. Departamentos de Geografía Humana y Geografía Física, Universidad Complutense, Madrid.

Moreno, A. (2010). Justicia ambiental. Del concepto a la aplicación en planificación y análisis de políticas territoriales. Revista electrónica de Geografía y Ciencias Sociales, Scripta Nova, XIV (316). Universidad de Barcelona.

Moreno, A. \& Cañada, R. (2007). Justicia ambiental y contaminación atmosférica por dióxido de azufre en Madrid: análisis espacio-temporal y valoración con sistemas de información geográfica. Boletín de la Asociación de Geógrafos Españoles, (44), 301-324. Recuperado de http://age.ieg.csic.es/boletin.htm.

Moreno, A. \& Martínez, P. (2005). El ruido ambiental urbano en Madrid. Caracterización y evaluación cuantitativa de la población potencialmente afectable. Boletín de la Asociación de Geógrafos Españoles, (40), 153-179. Recuperado de http://age.ieg.csic.es/boletin.htm

Organización Mundial de la Salud OMS. (2006) Guías de calidad del aire de la OMS relativas al material particulado, el ozono, el dióxido de nitrógeno y el dióxido de azufre. Ginebra; Suiza: OMS.

Organización Mundial de la Salud OMS (2011). Calidad del aire y salud. Centro de prensa, nota descriptiva. Recuperado de http://www.who.int/mediacentre/ factsheets/fs313/es/index.html

Quantum GIS Development Team. (2013) Quantum GIS Geographic Information System. Open Source Geospatial Foundation Project. Recuperado de http:// qgis.osgeo.org. 
Rodríguez, E., Etchavarría, N. \& Machado, M. (1982). Estructura social y organización espacial de la ciudad de Maracaibo. Maracaibo: Universidad del Zulia.

Romero, A., Montes, E. \& Franco, J. (2007). Aportes geográficos interdisciplinario en el estudio de la contaminación del aire. OMNIA Revista interdisciplinaria de la División de Estudios para Graduados de la Facultad de Humanidades y Educación, 13 (2), 30-55.

Sánchez, D. \& Egea, C. (2009). Vulnerabilidad sociodemográfica y ambiental, viejos y nuevos riesgos. Cuadernos Geográficos, 45, 2. Recuperado de http:// www.ugr.es/ cuadgeo/045.php.

Servicio Autónomo de Geografía y Cartografía Nacional. (1997). Atlas de Venezuela en línea. Edición de Cartografía Nacional, Caracas. [Disponible en CD].

United States Environmental Protection Agency. (2013). Efectos de los contaminantes comunes del aire. Recuperado de http://www.epa.gov/espanol/ciencia/ aire.html 